\title{
Patrimonio en tiempos revueltos
}

Carmen Guerra de Hoyos | Dpto. Historia, Teoría y Composición Arquitectónicas, Universidad de Sevilla

URL de la contribución <www.iaph.es/revistaph/index.php/revistaph/article/view/3864>

Querría comenzar la reflexión sobre el concepto del patrimonio en el presente desde un presupuesto que, de alguna manera, suponga un posicionamiento explícito. Así, describir nuestra situación sociocultural como tiempos revueltos, atiende no solamente al objeto patrimonial sino a la situación de los campos de conocimiento que se hacen cargo de su problemática.

La arquitectura, por ejemplo, está en un momento en el que se ve cuestionada como disciplina tanto desde el estatuto espacial, por superación del espacio artificial e hibridación constante con el espacio virtual, como desde el estatuto social, por los cambios constantes en los modos de vida y los valores de la sociedad de consumo. $\mathrm{Si}$ a esas dos grandes transformaciones le añadimos la renovación incesante de los sistemas constructivos y materiales por la aceleración tecnológica, tenemos un panorama inquietante en el que nos cuesta mucho establecer certezas o puntos de referencia no solo en temas patrimoniales sino en cualquier ámbito teórico de la disciplina arquitectónica.

No obstante, y pese a ese condicionante, intentaremos marcar algunos elementos de orientación que puedan ayudarnos a responder a las preguntas enunciadas para el debate sobre el patrimonio en el presente.

Para la primera de ellas quiero traer una referencia de José Luis Pardo, y contrastarla con la imagen del Angelus Novus de Benjamin:

"...la pluralidad de este tipo de fórmulas sucesivas y alternativas, rápidamente agotadas sin embargo (como los 'neo-', los 'post-', los 'micro-', los 'ultra-', los 'intra', los 'trans-', los 'tele-', los 'tardo-', etc) pudiera tener que ver con una cierta imposibilidad y una cierta impotencia de los tiempos modernos para pasar, para dejar paso a otros tiempos que no sean ya modernos. Esto es lo que significaría este rápido desgaste, estos intentos de pasar. Pero por otra parte, el hecho de que los intentos se multipliquen y los rótulos emerjan unos tras otros también debe de expresar, en cierto modo, el angustioso deseo de los hombres modernos de asistir al final de nuestros tiempos y de inaugurar una nueva época que, en cierto modo, estos prefijos solo intentan anticipar e intentan adelantar, siendo todo ello el testimonio del reiterado fracaso a la hora de habilitar un tiempo que sea nuevo y, sin embargo, la necesidad de crear constantemente nuevos rótulos con la esperanza de que esta vez el nuevo rótulo tenga éxito y de verdad anticipe o adelante un tiempo que ya no sea exactamente un tiempo moderno (...) ¿no podría ser que esto de `estamos transitando hacia un nuevo paradigma' fuera el emblema genuino de una de las principales experiencias de la modernidad, la experiencia de la transición, la experiencia de la transformación -aunque sea mucho más difícil el pensar hacia qué estamos transitando o desde dónde nos estamos transformando-, incluso hasta el punto de que estas preguntas (¿hacia qué? ¿desde dónde?) sean preguntas superfluas porque, de alguna manera, estamos instalados permanentemente en la transición?" (PARDO, 2011: 354-355).

El texto, en cierto modo, explica la posición del Ángel de la Historia. Mirar hacia atrás (horrorizado además) tiene como sentido primero marcar un futuro que se define precisamente desde un cierre de ese pasado en nuestro propio tiempo. Somos los últimos de un tiempo cerrado, fundamentalmente porque también queremos ser los primeros en alumbrar y anunciar otra época.

Como el propio Pardo señala es una posición ambigua porque, al fin y al cabo, ese momento iluminado entre la conciencia terrible del pasado y la esperanza de un nuevo amanecer no es un momento concreto, un cabo que se rebasa y a partir de entonces es ya futuro, sino 


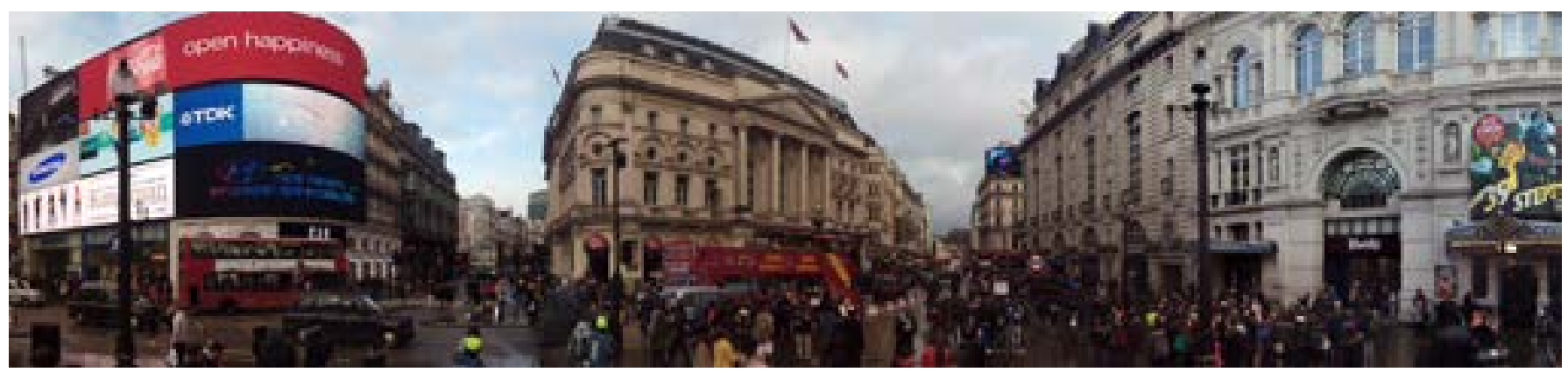

Las culturas locales conviven en nuestro presente con los modos de vida globales. Picadilly Circus, Londres, Reino Unido | foto Pablo F. J.

que se dilata y se eterniza sin término. La imposibilidad de cerrar ese momento supone también un extrañamiento continuo con el pasado y con el futuro, puesto que necesitamos mantener la distancia con el pasado por nuestra propia condición moderna y la incertidumbre sobre el futuro nos impide ser otra cosa que un paréntesis en constante auto revisión.

La distancia que observa Pardo no es sólo una distancia temporal, sino también espacial, puesto que esa separación la realizamos también respecto a las diferencias entre culturas, a la diversidad en los modos de uso del espacio, el concepto de identidad, o de la misma relación con el pasado, como nos recuerdan los estudios postcoloniales. Como si el Ángel de la Historia se girara en un círculo, reaccionando también respecto a las culturas locales, que conviven en nuestro presente con los modos de vida globales.

Centrándonos ya en el tema del patrimonio, el mantenimiento constante de la distancia entre pasado y presente, que nos da la certidumbre de nuestra propia modernidad, también genera la conciencia de un pasado "que ya no podemos resucitar, puesto que en cuanto tales, es decir, en cuanto perdidos, en cuanto irrecuperables, están preservados en su propia perdición y en su propia irrecuperabilidad y permanecen asidos a nuestra experiencia del tiempo..." (PARDO, 2011: 362).

Así el patrimonio en nuestra cultura está marcado por la separación y el extrañamiento, por lo que la pregunta sería ¿cómo tratar con lo extraño? ¿cómo acercarnos a lo que siempre alejamos de nosotros? Me acerqué a esa temática en un breve texto publicado en el blog $L a$ Ciudad Viva ${ }^{1}$. Del argumento allí planteado rescato un segundo punto de apoyo de un texto de Jean Luc Nancy, en el que analiza la reacción de María Magdalena ante Jesucristo una vez resucitado, al no reconocerle:

"Por una parte, todo sucede como si su semejanza consigo mismo estuviera por un momento suspendida y flotante. Es el mismo ser sin ser el mismo, está alterado en sí mismo: ¿no es así como se aparece un muerto?¿No es esta alteración a la vez insensible y sorprendente -el aparecer de lo que (del que) propiamente no aparece ya, el aparecer de un aparecido y desaparecido- lo que lleva más propia y violentamente la huella de la muerte? El mismo que no es ya el mismo, la disociación del aspecto y la apariencia, la ausencia del rostro en la misma cara, el cuerpo hundiéndose en el cuerpo, deslizándose bajo él. La partida inscrita en la presencia, la presencia presentando su despedida" (NANCY, 2006: 47).

El problema que detecta Nancy en el Ensayo sobre el levantamiento del cuerpo sobre la representación del contacto entre un cuerpo real y uno fantasmático (resucitado) podría ser trasladable a nuestra relación con el patrimonio, desde la perspectiva de la lejanía y la extrañeza que hemos rescatado con el texto de José Luis Pardo. ¿Cómo relacionar cosas que están en planos espaciales y temporales diferentes? Si la condición más propia de la modernidad es alejarnos constantemente del pasado ¿no tendríamos que asumir el extrañamiento como el rasgo más característico del patrimonio? 


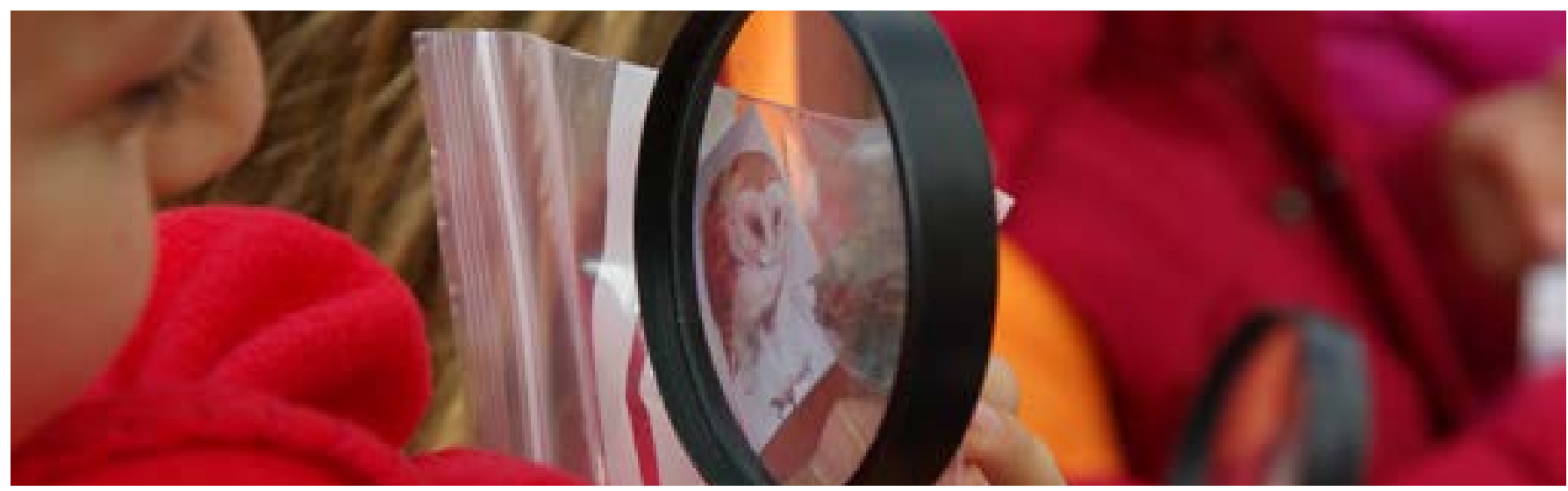

Se ha de abrir el debate patrimonial a una multiplicidad de intérpretes y de actores y extender sus sentidos no solo a los objetos, sino a la mirada patrimonialista. CEMA Venta Mina-Buñol. Rutas teatralizadas. Abril 2013 | foto Fundación Caja Mediterráneo

Si reflexionamos un poco sobre lo paradójico de esta condición puede parecer que la condición fantasmática no pertenece tanto al pasado, como a lo incierto e inabarcable de nuestro propio presente, a la incapacidad de reconocer el tiempo mismo donde habitamos. Frente al presente, el pasado se nos presenta como un tiempo de seguridades, erradas o no, que quedan presas en sus restos materiales y de ahí nuestra búsqueda de autenticidad y verdad en las interpretaciones patrimoniales.

Pero aunque podamos elucubrar sobre cuál de los sujetos del diálogo es más huidizo o menos consistente, lo que importa es el alcance que puede llegar a tener ese diálogo entre pasado y presente. Ahí es donde Nancy vuelve en nuestra ayuda para decirnos que el intento de la Magdalena de tocar al resucitado no solo sirve para dar el testimonio de lo visto (a otros tiempos, a otros espacios), sino también para aprender a tocar, para experimentar de modo más intenso nuestra relación con las cosas. Ir más allá de las diferencias temporales y locales y tocar lo que se sabe ya perdido para siempre nos cambia, desdibuja nuestros prejuicios y nos permite aprender sobre nuestra propia identidad, que se pone en juego en el ejercicio del diálogo.

No debería importar demasiado hasta qué punto el extrañamiento se produce desde una técnica, desde una verdad instrumental o política, sino si la operación de recuperación es reversible o no, es accesible desde diferentes actores, o se integra en el soporte experiencial de la ciudadanía. De ahí la necesidad de abrir el debate patrimonial a una multiplicidad de intérpretes y de actores, y de extender sus sentidos no solo a los objetos, sino a la mirada patrimonialista, pero sabiendo que, cuando lo hacemos, aumentamos el arco de aquellas cosas que se alejan de nosotros, puesto que el concepto patrimonio en la modernidad opera desde el extrañamiento. Y el extrañamiento, como descubrieron los románticos, es la base constitutiva de la vivencia, y por tanto de la construcción de la propia identidad, aunque no sea una tarea tranquilizadora ni segura.

Como podemos comprobar con un tercer apoyo en el concepto de romantizar de Novalis, leído por Alfredo de Paz:

"No se trata, por tanto, de la invención poética de nuevos mundos, de nuevos objetos o relaciones, sino de la Verfremdung, del extrañamiento del mundo antiguo, que hace que todo lo dado, lo predeterminado, lo normalizado aparezca bajo una nueva luz: lo natural, lo habitual se convierte en extraño y problemático, mientras que lo extraño, lo olvidado, lo enigmático -todo lo apartadose convierte (o tiende a convertirse) en familiar, extrañamente familiar. En ese sentido, si, románticamente, a través del arte de la excitación del ánimo, alcanzamos 
esa 'dimensión estética', donde el pensamiento de la identidad es llevado hasta el límite extremo de lo posible (hasta los límites de lo imposible) y donde se interrumpe el automatismo de la acción y de la percepción, entonces podemos salir del círculo de la falta de libertad que nos encadena a lo cotidiano y a lo establecido, que nos tiene en su poder y nos hace aceptar una vida encantada y coartada por potencias desconocidas, como un destino natural e ineluctable. El arte de la excitación del ánimo, el arte de la romantización, el uso activo de todos los órganos, debe ser entendido política y sociológicamente en el sentido de una transformación necesaria y radical del hombre y de la sociedad, a pesar de carecer de un modelo tranquilizador, de una lámpara prefabricada que ilumine los caminos del porvenir" (PAZ, 1992, p 208).

No parece poca recompensa para la tarea patrimonial esta misión de devolvernos la libertad mediante el extrañamiento vivencial. Por ello me parece sugerente rescatar esta perspectiva para el debate, pese a las incertidumbres y las dificultades que entraña entender el patrimonio como instrumento de una "transformación necesaria y radical del hombre y de la sociedad".

\section{BIBLIOGRAFÍA}

- NANCY, J. (2006) Noli me tangere. Ensayo sobre el levantamiento del cuerpo. Madrid: Trotta, 2006

- PARDo, J. L. (2011) Disculpen las molestias, estamos transitando hacia un nuevo paradigma. En ARENAS, L.; FOGUÉ, U. (ed.) Planos de (Inter)sección: materiales para un diálogo entre filosofía y Arquitectura. Madrid: Lampreave, 2011

- PAZ, A. DE (1992) La revolución romántica. Poéticas, estéticas, ideologías. Madrid: Tecnos, 1992

\section{NOTAS}

1. Disponible todavía para su lectura en http://www. laciudadviva.org/blogs/?p=2145 [Consulta: 25/01/2017].

2. "El mundo debe hacerse romántico. Sólo de este modo encontrará su significado original. Hacerse romántico, 'romantizar' no es otra cosa que una potenciación cualitativa (...) En el mismo instante en que yo atribuyo a lo vulgar un significado sublime, lo convierto en romántico y cuando doy a lo común una apariencia misteriosa, a lo conocido la dignidad de lo desconocido, a lo finito el aspecto de lo infinito, lo romantizo." Novalis, 1795-1800, F.L. p. 63, citado en PAZ, 1992: 208. 